\title{
PENERAPAN RAGAM HIAS BATIK MEGA MENDUNG PADA DESAIN KEMASAN BOTOL AIR MINERAL
}

\author{
Riean Fairuz Zahran', Teguh Kurnia Ramadhan ${ }^{2}$ \\ Program Studi Desain Komunikasi Visual, \\ Fakultas Bahasa Dan Seni, Universitas Indraprasta PGRI \\ Jl. Nangka 58 C Tanjung Barat, Jakarta Selatan, 12530, Indonesia
}

Email: riean.fz24@gmail.com

\begin{abstract}
Abstrak
Seiring dengan perkembangan zaman kemasan tidak lagi semata sebagai pelindung tetapi, sebagai ciri khas atau pembeda dengan produk pesaing agar produk mudah diingat oleh masyarakat serta dapat meningkatkan penjualan produk di pasaran. Selain itu, kemasan bisa menjadi wadah penerapan kreativitas atau karya seni. Dalam penulisan kali ini penulis menerapkan karya seni nusantara yaitu ragam hias batik Mega Mendung pada sketsa kemasan produk botol air mineral. Motif ragam hias Mega Mendung identik dengan bentuk awan dan menjadi ikon batik daerah Cirebon. Penelitian ini bertujuan untuk memperkenalkan kembali ragam hias yang ada di Indonesia khususnya ragam hias batik Mega Mendung. Metode yang digunakan dalam penelitian ini yaitu dengan pendekatan kualitatif. Hasil dari penelitian ini berupa pengenalan unsur visual dari motif batik Mega Mendung yang kemudian akan diterapkan pada desain kemasan botol air mineral dengan motif ragam hias tersebut.
\end{abstract}

Kata kunci: Kemasan, Botol, Ragam Hias, Mega Mendung

\begin{abstract}
Along with the development of the packaging era is no longer merely a protector but, as a characteristic or differentiator with competing products so that the product is easily remembered by the public and can increase product sales in the market. In addition, the packaging can be a container for the application of creativity or artwork. In this writing, the writer applies the archipelago artwork, namely the Mega Mendung batik decoration on the sketch of the bottled mineral water product packaging. Mega Mendung decorative motifs are identical to the shape of clouds and become an icon of batik in Cirebon. This study aims to reintroduce the existing decoration in Indonesia, especially the Mega Mendung batik decoration. The method used in this research is a qualitative approach. The results of this study include an introduction to the visual elements of the Mega Mendung batik motif which will then be applied to the design of bottled mineral water with these decorative motifs.
\end{abstract}

Keywords: Packaging, Bottles, Ornamental Variety, Mega Mendung

Correspondence author: Riean Fairuz Zahran, riean.fz24@ gmail.com, Jakarta, and Indonesia

This work is licensed under a CC-BY-NC 


\section{PENDAHULUAN}

Nusantara merupakan tempat bagi berbagai macam kesenian dan kebudayaan yang menjadikan Indonesia negara dengan kemajemukan budaya yang sangat kuat. Setiap kesenian daerah memiliki keunikan dan ciri khas tersendiri yang merupakan kekuatan Indonesia yang tidak dimiliki negara lain. Kesenian daerah yang terus dijaga dan dipertahankan akan memperkuat ciri khas dan jati diri sebuah bangsa. Itu semua didapatkan melalui proses yang dihasilkan secara turun temurun dan dilakukan selama bertahun-tahun lamanya, sehingga sangat sulit menjaga keaslian dan mempertahankan kebudayaan tersebut. Kesenian yang tetap ada sampai saat ini merupakan kebudayaan yang masih bisa diterima sesuai dengan perkembangan zaman. Berbagai macam kesenian tersebar di seluruh pelosok nusantara. Setiap daerah memiliki kesenian dan kebudayaan tersendiri yang menjadi ciri khas dan identitasnya masing-masing.

Kesenian daerah yang cukup terkenal adalah ragam hias batik Mega Mendung. Ragam hias atau ornamen secara etimologi berasal dari bahasa Yunani, dari kata ornere yang berarti kerja menghias dan ornamentum yang berarti hasil karya atau hiasan. Ragam hias pada dasarnya merupakan penghias yang dipadukan, sebagai media mempercantik atau mengagungkan suatu karya (Baidlowi \& Daniyanto, 2003). Ragam hias Mega Mendung berasal dari Jawa Barat, lebih tepatnya berasal dari Cirebon. Cirebon merupakan salah satu daerah penghasil batik di Jawa Barat yang memiliki kekuatan dalam penggambaran setiap motifnya. Batik merupakan salah satu bentuk ekspresi kesenian tradisi yang dari hari ke hari semakin menapakkan jejak kebermaknaannya dalam khasanah kebudayaan Indonesia. Secara etimologi istilah batik berasal dari kata yang berakhiran "tik", berasal dari kata menitik yang berarti menetes yaitu menitikkan malam dengan canting sehingga membentuk corak yang terdiri atas susunan titikan dan garisan (Anas, 1997).

Masina adalah salah satu pembatik Mega Mendung. Ia merupakan pembatik yang berasal dari daerah Trusmi Cirebon. Masina merupakan keturunan pembatik Trusmi yang sudah mulai membatik sejak 1942. Desa Trusmi adalah salah satu desa yang pada awalnya tumbuh sebagai desa dalam tradisi kebudayaan lokal, yang kemudian berkembang dalam pengaruh kebudayaan hindusitik. Perubahan status dari desa menjadi kadipaten di bawah Kasultanan Cirebon berarti pula secara efektif Islam sebagai religi masuk ke dalam kebudayaan masyarakat Trusmi (Supriyadi, Wijayanti, Adimuyanto \& Utaryo, 2001). Jenis-jenis corak batik Trusmi Masina didasarkan pada perwujudan kelompok-kelompok corak yang masih ada, hingga tetap terkenal di samping menjadi sumber ilham pembentuk corak baru. Terdapat 24 corak batik yang ditemukan corak Batik Trusmi Masina, Cirebon (dengan corak batik pribumi Trusmi). Penerapan dari berbagai macam bentuk coraknya didasarkan pada pembagian pengelompokan masing-masing corak yang terwakili. Dari berbagai corak tersebut disimpulkan dua unsur bentuk dan warna yang mewakili Batik Trusmi Masina, Cirebon (Kusumowardhani, 2016). Terdapat tiga bentuk dasar yang sering muncul pada enam Batik Trusmi, Masina, Cirebon, yakni; awan, sayap dan daun. Bentuk awan merupakan bentuk yang khusus terdapat pada batik Mega Mendung. Bentuk awan merupakan bentuk yang khusus terdapat pada batik Mega Mendung, dan muncul pula pada lima dari ke enam batik pilihan. Berikut adalah bentuk corak yang menjadi salah satu ciri identitas bentuk khas corak Batik Trusmi, Masina Cirebon (Kusumowardhani, 2016).

Botol kemasan air mineral akan didesain menggunakan ragam hias batik Mega Mendung Trusmi dengan bentuk dasar unsur visual dari corak motif tersebut. Kemasan adalah desain kreatif yang mengaitkan bentuk, struktur, material, warna, citra, tipografi dan elemen-elemen desain dengan informasi produk agar produk dapat dipasarkan. Kemasan digunakan untuk membungkus, melindungi, mengirim, mengeluarkan, menyimpan, mengidentifikasi dan membedakan sebuah produk di pasar (Klimchuk dan Krasovec, 2006). Pengaplikasian motif corak pada kemasan botol biasanya mengandalkan motif yang dinamis karena dirasa cocok dalam bentuk yang praktis. Dalam perancangan kali ini penulis merasa motif ragam hias Mega Mendung juga dapat terlihat dinamis dan menambah keindahan pada kemasan botol. Dengan adanya pengembangan desain produk kemasan botol yang menggunakan penerapan unsur-unsur visual pada batik Mega Mendung Trusmi, diharapkan dapat meningkatkan nilai tambah pada 
produk yang dihasilkan dengan mengedepankan unsur-unsur visual yang disebutkan oleh Marvin Bartel (1999) "The cheramic artist and retired provesor of art Goshen College", dalam bukunya "Elements and Principle of Design", pengaruh alam semesta digambarkan dalam bentuk-bentuk meru, tumbuhan, binatang, bangunan serta lidah api di samping bentuk-bentuk geometris dan bentuk dengan garis miring. Perlambangannya tidak hanya menggambarkan kehidupan-kehidupan alam nyata semata, tetapi pengungkapan bentuk pola-pola tersebut merupakan suatu kecenderungan dari adat istiadat, bentuk alam dan kejadian sehari-hari yang kemudian menjadi perlambangan sehingga mempunyai makna tertentu yang erat hubungannya dengan pandangan hidup manusia, yakni suatu perwujudan nyata dari kekuatan-kekuatan yang ada.

\section{METODE PENELITIAN}

Penulis menggunakan metode penelitian kualitatif. Metode penelitian kualitatif berusahan memahami dan menafsirkan makna suatu peristiwa interaksi tingkah laku manusia dalam situasi tertentu menurut perspektif peneliti sendiri. Penelitian dengan metode kualitatif bertujuan untuk memahami objek yang diteliti secara mendalam, mengembangkan konsep sensitivitas pada masalah yang dihadapi, menerangkan realitas yang berkaitan dengan penelusuran teori dari bawah (grounded theory) dan mengembangkan pemahaman akan satu atau lebih dari fenomena yang dihadapi (Gunawan, 2013).

Metode yang digunakan adalah analisis deskriptif. Artikel ini diteliti secara ilmiah menggunakan pendekatan sekunder dengan sumber data yang didapatkan dari artikel, jurnal, dan ebook dari internet. Penulis juga menggunakan pendekatan desain komunikasi visual dalam pembahasan mengenai penerapan desain pada kemasan. Penulisan artikel ini akan menjelaskan mengenai ragam hias Indonesia khususnya batik Mega Mendung yang kemudian ragam hias tersebut akan diterapkan pada desain kemasan botol air mineral. Penulis memberikan sketsa desain ragam hias Mega Mendung yang diterapkan pada kemasan botol air mineral.

\section{HASIL DAN PEMBAHASAN}

Hasil dari penelitian ini berupa desain dari botol kemasan air mineral dengan penerapan ragam hias motif Mega Mendung. Penulis mencari beberapa contoh desain kemasan botol beberapa produk air minum dalam kemasan. Hal ini dimaksudkan sebagai referensi bentuk botol yang akan digunakan dalam pengaplikasian motif ragam hias Mega Mendung untuk desain kemasan botol air mineral. Kemasan botol yang menjadi referensi diambil dari merk air mineral dalam kemasan yang sudah cukup terkenal yaitu AQUA, Le Minerale, dan Ades.

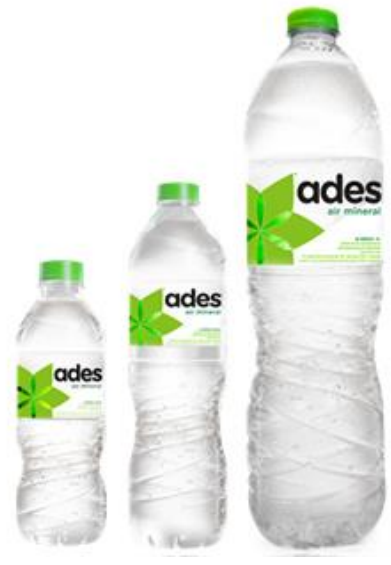

Gambar 1 Botol AdeS Sumber: coca-colaamatil

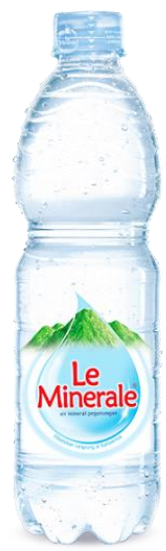

Gambar 2 Botol Le Minerale Sumber: leminerale.com

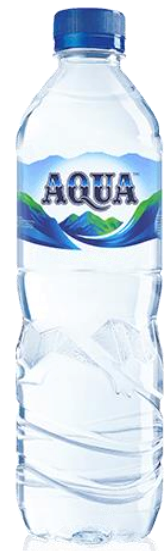

Gambar 3 Botol AQUA Sumber: sehataqua.co.id 
Dari referensi diatas menghasilkan desain bentuk kemasan botol air mineral yang belum diterapkan motif dan elemen kemasan lainnya. Berikut hasil desain bentuk kemasan botol air mineral yang sudah dirancang.

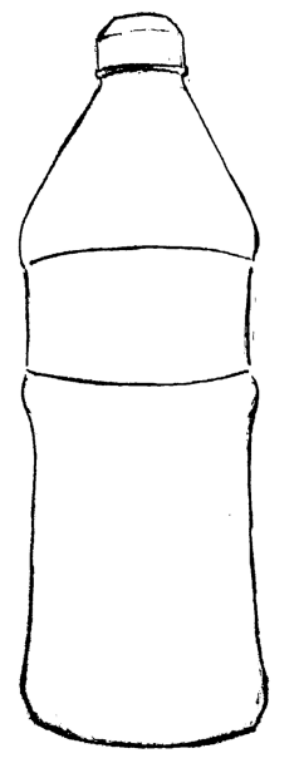

Gambar 4 Desain Botol

Sumber: Dokumentasi Penulis

Desain botol tersebut akan menjadi media penerapan motif batik Mega Mendung. Penerapan motif batik Mega Mendung pada kemasan botol air mineral diambil bentuk dasar visual dari motif ragam hias batik Mega Mendung yang identik dengan bentuk lengkungan seperti bentuk awan, sayap dan daun.

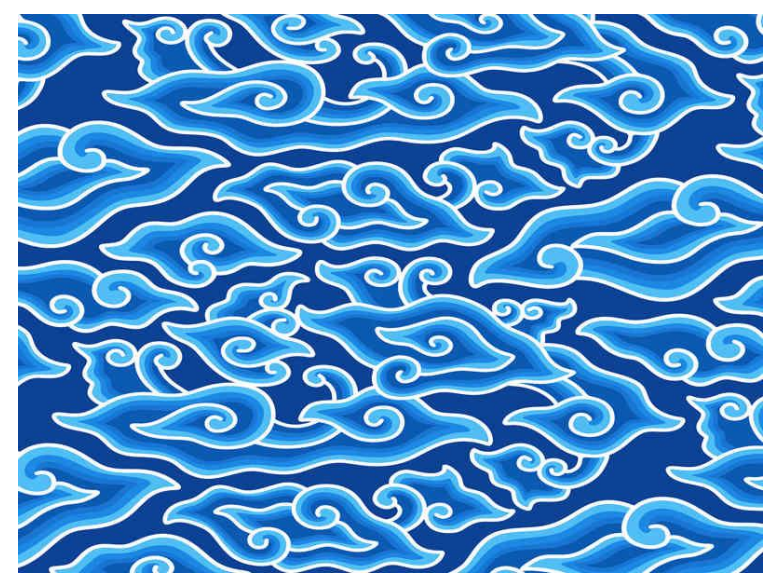

Gambar 5 Batik Mega Mendung Sumber: advancedbiofuelssummit.com
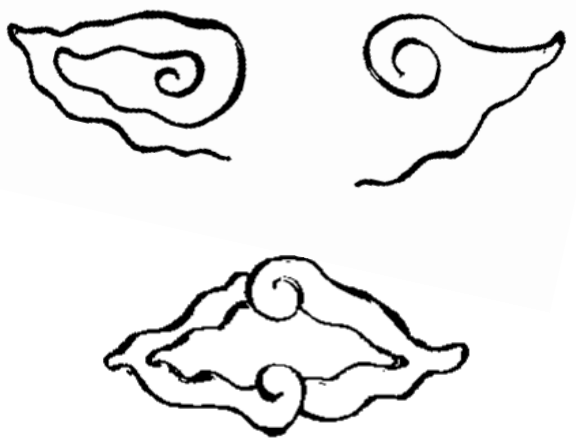

Gambar 6 Unsur Visual Mega Mendung Sumber: Dokumentasi Penulis

\section{Desain Botol Kemasan Air Mineral dengan Motif Ragam Hias Mega Mendung}

Desain botol dan visual motif ragam hias Mega Mendung dirancang sampai menjadi sebuah desain botol air mineral dengan motif ragam hias Mega Mendung, dengan penerapan 
pada beberapa bagian botol yaitu tutup botol, label, dan bagian badan botol. Berikut adalah desain botol kemasan air mineral yang sudah diterapkan Motif Ragam Hias Mega Mendung.

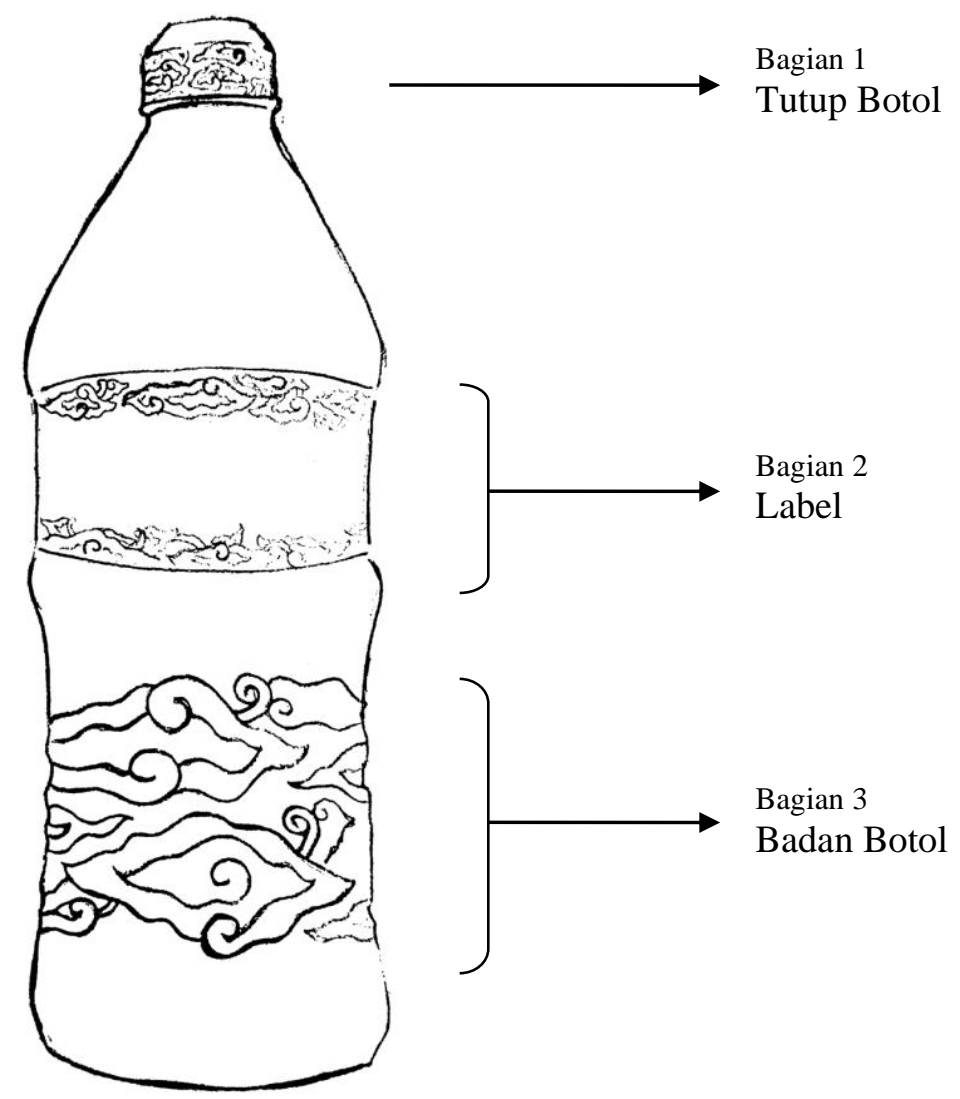

Gambar 7 Desain botol dengan motif Sumber: Dokumentasi Penulis

\section{Bagian 1 Tutup Botol}

Tutup botol dibuat dengan desain yang modern. Ilustrasi motif ragam hias dibuat mengelilingi tutup botol dengan sentuhan 3 dimensi sehingga menghasilkan tekstur yang bisa diraba atau disentuh ketika konsumen membuka tutup botol.

\section{Bagian 2 Label}

Pada desain label tidak jauh berbeda seperti biasanya, seperti nama merk, komposisi, kandungan dan sebagainya. Keunikan pada label botol ini adalah terdapat motif ragam hias Mega Mendung pada bagian atas dan bawah yang mengelilingi botol. Warna yang digunakan pada label adalah dominasi warna biru. Hal itu disesuaikan dengan warna motif Mega Mendung. Selain itu, warna biru juga merepresentasikan warna air yang alami dan segar.

\section{Bagian 3 Badan Botol}

Bagian badan botol merupakan salah satu bagian utama lainnya yang cukup penting, karena pada bagian ini sangat terlihat dan pada bagian ini pula penerapan motif ragam hias Mega Mendung sangat ditekankan. Motif Mega Mendung melingkar pada bagian badan botol dengan desain 3 dimensi sehingga tekstur dari motif dapat dirasakan jika botol digenggam atau dipegang. Bagian ini yang menjadi daya tarik untuk konsumen karena keuniakan motif ragam hias nusantara yang diterapkan pada media selain kain atau media datar lainnya. Bagian badan 
botol ini tidak memiliki warna (bening) menyesuaikan warna botol agar kejernihan air tetap terlihat.

\section{SIMPULAN}

Saat ini, fungsi kemasan tidak hanya sebagai pelindung atau pembungkus dari suatu produk, tetapi dapat dijadikan sebagai media karya seni, salah satunya adalah botol kemasan air mineral. Botol kemasan dengan motif ragam hias batik Mega Mendung merupakan salah satu pengaplikasian karya batik nusantara khususnya Mega Mendung ke dalam media baru. Motif yang sangat indah ini dilestarikan serta diperkenalkan kepada masyarakat umum agar terus terjaga, dapat dikenal, serta dilestarikan oleh generasi penerus. Selain memperkenalkan motif batik Mega Mendung alasan lain penggunaan motif Mega Mendung pada botol air mineral juga karena motif tersebut mengandung makna yang sangat indah. Motif Mega Mendung melambangkan awan mendung yang dapat berarti harapan hujan yang berupa rezeki. Hujan bagi masyarakat perdesaan khususnya Cirebon yang hidup secara agraris memiliki peran sentral dalam kehidupan mereka, yaitu sebagai perlambangan turunnya rezeki, kesuburan tanah, dan keberhasilan hasil tanam. Oleh karena itu, bentuk awan bisa dianalisis sebagai bentuk yang mewakili kebudayaan batik Trusmi Masina. Air hujan membawa kesuburan, begitu pula air minum yang ada pada kemasan ini membawa kesegaran, sehingga motif yang digunakan sangat berhubungan dengan yang ada di dalamnya. Keunikan yang terdapat pada kemasan botol ini juga menjadi salah satu daya tarik yaitu dengan adanya tekstur 3 dimensi pada motif batik Mega Mendung yang ada pada kemasan sehingga konsumen dapat merasakan tekstur ketika botol ini digenggam.

Dapat disimpulkan bahwa pengenalan motif ragam hias nusantara khususnya batik Mega Mendung dapat menggunakan berbagai macam media, salah satunya botol kemasan air mineral. Dengan adanya pengenalan motif ragam hias nusantara ini, diharapkan masyarakat akan lebih mengenal dan melestarikan ragam hias nusantara yang begitu banyak, salah satunya motif batik Mega Mendung.

\section{DAFTAR PUSTAKA}

Anas, B. (1997). Indonesia indah: Batik. Yayasan Harapan Kita/ PB 3 TMII, Jakarta.

Baidlowi, H., \& Daniyanto, H. (2003). Arsitektur permukiman Surabaya. Surabaya: Karya Harapan.

Bartel, M. (1999). Elements and principle of design. Goshen College Press.

Gunawan, I. (2013). Metode penelitian kualitatif. Jakarta: Bumi Aksara.

Kusumowardhani, P. (2016). Aplikasi unsur visual ragam hias batik trusmi masina Cirebon pada perangkat makan. Jakarta. Polimedia Publishing.

Kusumowardhani, P. (2016). Identifikasi unsur visual bentuk dan warna yang menjadi ciri khas batik trusmi masina Cirebon. Politeknik Negeri Bandung.

Klimchuk, M., \& Krasovec, S. A. (2006). Desain kemasan. Jakarta.

Supriyadi, B., Wijayanti., Adimuyanto, E., \& Utaryo, H. P., (2001). Karakteristik akulturasi budaya dalam arsitektur rumah tinggal dan pola tata ruang di Desa Trusmi Cirebon. Universitas Diponegoro. 